\section{On Wells's (1792) law of visual direction}

\section{HIROSHI ONO \\ York University, Downsview, Ontario M3J IP3, Canada}

Let optic axis be defined by a line passing through "an object so placed as to be seen more distinctly than in any other situations" (Wells, 1792, p. 38) and a point that would be "interposed between the former and the eye" (1792, p. 38), visual base by "the interval between the points of the cornea where the axes enter the eyes" (1792, p. 38), and common axis by a "line from the middle of the visual base, through the point of intersection of the axis" (1792, p. 39).'

"Proposition I. Objects situated in the Optic Axis, do not appear to be in that Line, but in the Common Axis" (1792, p. 40).

"Proposition II. Objects, situated in the Common Axis, do not appear to be in that Line, but in the Axis of the Eye, by which they are not seen" (1792, p. 46).

"Proposition III. Objects, situated in any Line drawn through the mutual Intersection of the Optic Axes to the Visual Base, do not appear to be in that Line, but in another, drawn through the same Intersection, to a Point in the Visual Base distant half this Base from the similar Extremity of the former Line, towards the left, if the objects be seen by the Right Eye, but towards the right, if seen by the Left Eye"'(1792, p. 50).

Upon examination, the above propositions appear to be another attempt to formalize Hering's (1879/ 1942) principles of visual direction. They are, however, direct quotations from Wells's $(1792,1818)$ Essay upon Single Vision with Two Eyes, and they declare well before the appearance of Hering's principles that "apparent directions of objects are governed by a law, different from any which has hitherto been thought to exist" (Wells, 1792, p. 55). Reference to this essay, however, is not made in Ono's (1979) attempts to formalize Hering's principles, even though the perceptual phenomena used to demonstrate the principles in Ono's paper were known to Wells and were discussed in his essay to validate the propositions.

The aim of this paper is to correct this oversight by (1) restating and illustrating the propositions (no illustration was used in Wells's essay), (2) comparing

This research was conducted at Dundee University, Dundee, Scotland, while the author was on Leave Fellowship from The Social Sciences and Humanities Research Council of Canada. He would like to thank his colleagues in perception at York University and at Dundee University for helpful comments on an earlier version of this paper.

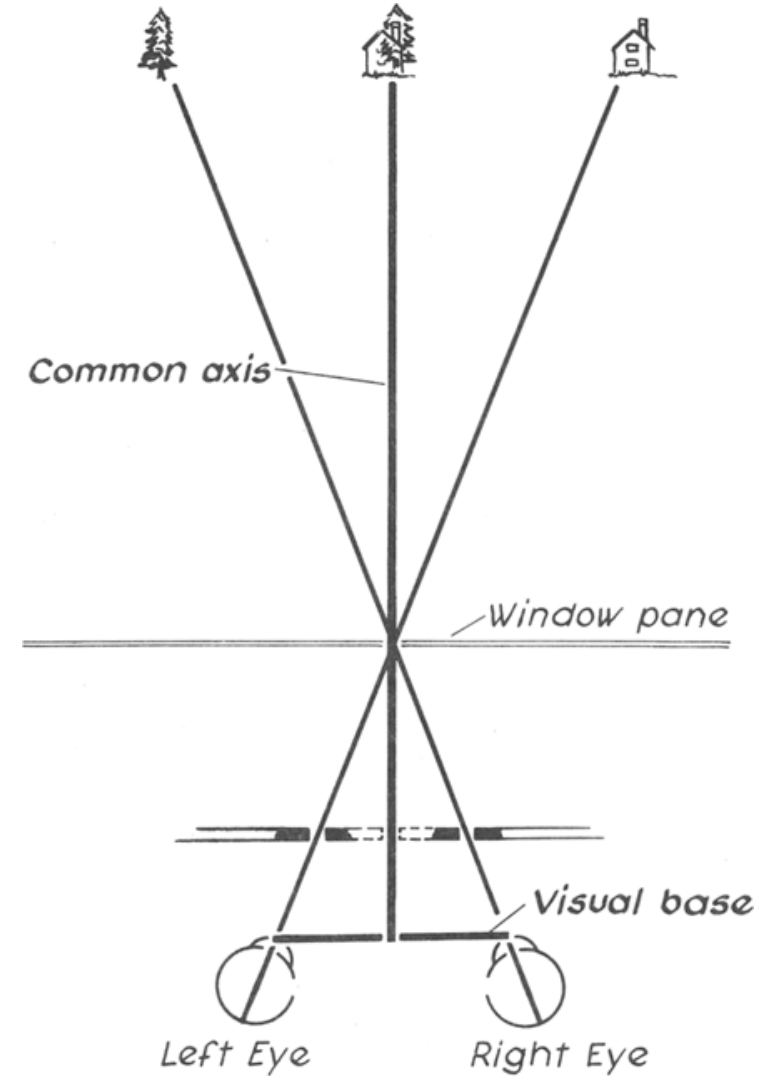

Figure 1. A demonstration of Wells's Proposition I with Hering's demonstration of principles of visusal direction.

Wells's propositions to Hering's principles, and (3) speculating why Wells's work is not generally known.

The illustration in Figure 1 shows one of the stimulus situations Wells discussed with respect to Proposition I, together with the situation often depicted to discuss Hering's principles of visual direction. Wells placed a card with two holes (one hole in each optic axis) in front of the eyes and observed a hole in the common axis in accordance with Proposition I. The phenomenon in Hering's demonstration is in accord with this proposition. For the situation depicted in Figure 1 , if an observer binocularly fixates on the marker on the window, the two holes of Wells's experiment as well as the tree top and chimney of Hering's demonstration are in one of the optic axes, and according to Proposition I they appear in the common axis.

Figure 2 illustrates one of the situations Wells discussed with respect to Proposition II. ${ }^{2}$ It shows how a hole (the square one) in the common axis and holes (the circular ones) in the optic axes would appear in illusory locations. According to Proposition II, the 


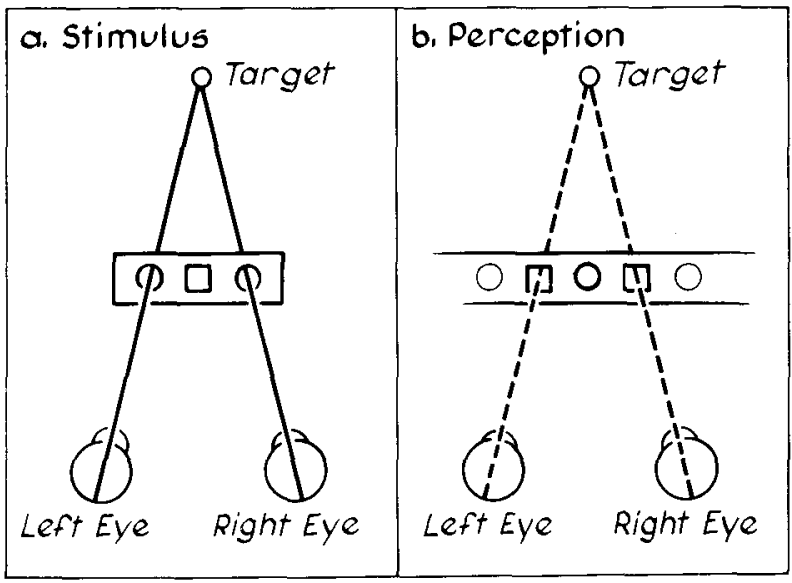

Figure 2. A demonstration of Propositions I and II. (The two outside circular holes are predicted by Proposition III.)

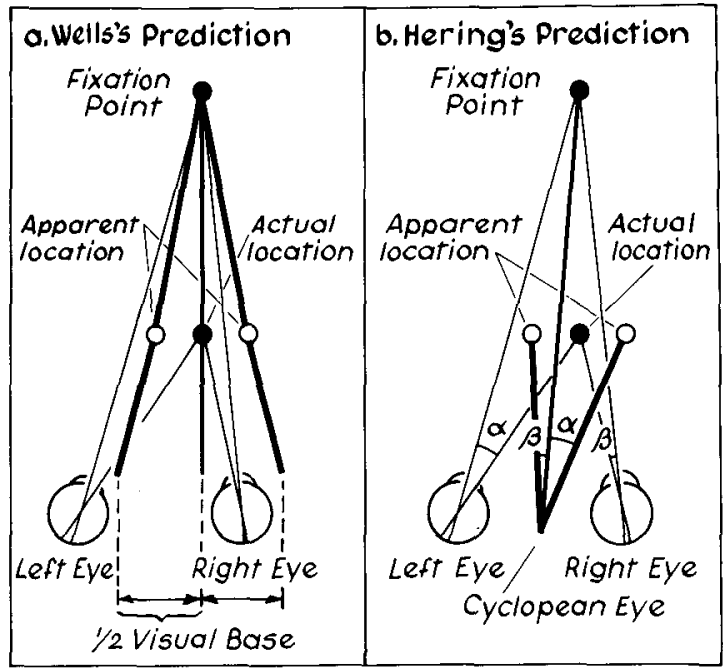

Figure 3. Predictions of apparent locations of diplopic images.

hole in the common axis is seen in each optic axis, and, according to Proposition $I$, the holes in the optic axes are seen as one in the common axis. Two holes, located one in each optic axis, are not necessary for testing Proposition II. They may have been used to fix the optic axes or to produce a perceptual "paradox" where an observer cannot see the target through the apparent locations of the holes in the visual axes. (This stimulus situation is not as easy to arrange as one might anticipate. The fixation target or the holes will be in illusory locations as predicted from the propositions, and an observer tends to move the card inappropriately. Furthermore, when attention shifts to the apparent location of the holes, the eyes tend to move away from the fixation target. Demonstration of the effect of Proposition I or Proposition II is easier with pieces of wire or lines on a sheet of paper, as discussed in Ono, 1979.)

The first two propositions are special cases of the third: that is, the first two can be deduced from the third. Thus, Proposition III is logically the only one required for Wells's theory. Figure 3a illustrates how the proposition can be used to determine the apparent locations of diplopic images. The proposition is applied here by (1) drawing a line through the fixation point and the location of a stimulus (Wells called this "the line of the object's real position"), (2) determining two points, on a line coincident with the visual base, which are half the length of the visual base on either side of the intersection of the "line of the object's real position" and the coincident line, and (3) from these two points, drawing lines through the fixation point. The prediction is that the diplopic images will be seen on these lines.

Figure 3b illustrates predictions from Hering's principle which "projects" to the cyclopean eye the visual angle subtended by two objects at an eye. According to Hering (1879/1942), "The direction in which the illusional images appear, is unalterably determined by the law of identical visual directions. If we conceive of the two real retinal images as transferred to the retina of the imaginary single eye (cyclopean), in a manner to make all cover points coincident, and let the lines of direction of the single eye pass for the visual lines of direction: each illusional image will have its own visual direction" (p. 74). In the figure, the angle subtended by the fixation point and an object to the left eye $(\alpha)$ and that subtended to the right eye $(\beta)$ are duplicated at the cyclopean eye. The prediction is that the diplopic images will be seen on the two outside lines.

Figure 3 also shows how close the predictions from the two theories can be. If an assumption is made that the distance of an object is correctly perceived, the predictions from them are almost identical for an object that is between or not far outside the two optic axes. They differ, however, in that Hering used hypothetical constructs, whereas Wells did not. Hering used such concepts as the cyclopean eye, corresponding points, and identical visual direction to explain the apparent locations of stimuli. In contrast, although Wells (1792) used similar wording in his essay, for example, "a law affecting both eyes considered as one organ" (p. 42) or "an object ... is seen by both eyes in one and the same direction" (p. 56), the propositions themselves are descriptive laws without constructs. ${ }^{3}$

This difference, however, does not explain why Wells's work was ignored by many 19th century workers in binocular vision (e.g., Brewster, 1844a, 1844b; Hering, 1879/1942; Le Conte, 1881; and Panum, 1858/1940). Wheatstone (1838) was one of the exceptions; he remarked, "So little does Dr. Wells's 
theory appear to have been understood, that no subsequent writer has attempted either to confirm or disprove his opinions" (p. 388). Wells may have contributed to this lack of understanding because, unlike Hering, he neglected to mention that the predictions from the propositions were not easily confirmed by a naive observer under normal viewing conditions (see Ono, 1979). But the lack of understanding alone does not explain the neglect. An examination of a few references made to Wells's work suggests other reasons.

Wheatstone praised Wells (an "acute writer") and his essay (it "contains many valuable experiments and remarks"), but he rejected Wells's theory, along with those by "Aguilonious, Dechales, and Porterfield," which claim that "objects are seen single only when they are in the plane of horopter"' (p. 388). The basis of the rejection by Wheatstone was that he had "given sufficient proof, in showing that, when the optic axes converge to any point, objects before or beyond the plane of the horopter are under certain circumstances equally seen single as those in that plane" (p. 388). This argument and conclusion is echoed in a 19th century textbook by MacKenzie (1841).

Mueller $(1840 / 1843)$ in the classic volume Elements of Physiology referred to Wells's work when discussing the extent of association between convergence and accommodation (p. 1148), but not when discussing binocular vision. This may be owing to Mueller's rejection of the idea that a horopter lies in a frontal parallel plane. Perhaps for the same reason, Helmholtz (1911/1952) did not mention Wells's work in his discussion of visual direction or binocular vision in the most frequently cited book in vision, The Handbook of Physiological Optics. (Wells is listed, however, in the bibliography section for binocular vision.)

If Wheatstone's reason and the one speculated for Mueller and Helmholtz are responsible for the lack of recognition, these influential writers did not do justice to Wells's work. In both cases, the domain of the theories is not considered. Wheatstone's argument holds inside what we now call the Panum area and Wells's propositions hold outside. Moreover, the Panum area does not follow either the Vieth-Mueller circle or the frontal parallel plane.

Two other factors only indirectly related to the substance of Wells's work may also have contributed to this neglect. One factor is Wheatstone's suggestion, perhaps an unintentional one, that Wells was unaware of Smith's (1738) observations which were similar to those that served as the basis of the propositions. This suggestion may have unjustly discredited Wells's essay. Wheatstone did not make clear that this lack of awareness applied only to the occasion when Wells first made the observation and not to when he actually wrote the essay. Referenced in the essay are Smith's observations that a ruler placed in the median plane would appear double and that two legs of a compass, one placed close to each optic axis, would appear in the common axis (1792, see pp. 10, 13,14 , and 16). The other factor is the absence of illustration in Wells's essay. This is suggested because Smith's second observation with the reproduction of the original illustration is still being cited today (Gulick \& Lawson, 1976). If this is the case, it is hoped that the illustrations in this paper and those in Ono (1979) will rectify the possible consequence of the omission.

The lack of recognition extends to Wells's other studies in vision; a case in point is his extensive observations on the motion of afterimages. He observed and discussed the absence of apparent movement of an afterimage with passive eye movement, and noted the role of voluntary eye movements. He concluded that "the apparent direction of an object ... depends upon the state of action existing at the same time in the muscles of the eye, and consequently that it cannot be altered, except by a change in the state of that action" (1792, pp. 70-71). Although this quotation is not a statement of modern "outflow" theory of visual direction, a case can be made that Wells is the father of "outflow" theory and that he provided the data and the idea that served as a stepping-stone for Bell $(1803,1823)$ and Helmholtz (1911/1925) (cf. Wade, 1978), although even this important observation and the idea are not credited to him. ${ }^{4}$

The foregoing discussion implies that Wells deserves greater recognition as the first person to state the law of binocular visual direction and as a creative worker in visual science. His other scientific work has received belated recognition. The entry for Wells in the Dictionary of Scientific Biography (1970) notes that his (1814) theory on dew formation was not generally accepted until 1885; the one in the Dictionary of American Biography (1957) notes that his $(1813 / 1818)$ statement of the principle of natural selection was not credited to him by Charles Darwin as the first such statement until the fourth edition (1866) of the famous Origin of Species. We should now recognize Wells for his pioneering work in vision as well.

\section{REFERENCES}

BELl, C. An anatomy of the human body (Vol. 3). London: Longman, Rees, Cadell \& Davies, 1803.

BeLl, C. On the motions of the eye, in illustration of the uses of the muscles and of the orbit. Philosophical Transactions of the Royal Society, 1823, 113, 166-186.

BREWSTER, D. On the law of visible position in single and binocular vision, and on the representation of solid figures by the union of dissimilar plane pictures on the retina. Transactions of the Royal Society of Edinburgh, 1844, 15, 349-388. (a)

Brewster, D. On the knowledge of distance given by binocular vision. Transactions of the Royal Society of Edinburgh, 1844, 15, 663-674. (b)

DARWIN, C. On the origin of species by means of natural selec- 
tion, or the preservation of favoured races in the struggle for life (4th ed.). London: J. Murray, 1866.

Dictionary of American biography (American Council of Learned Societies). New York: Scribner's, 1957.

Dictionary of scientific biography (American Council of Learned Societies). New York: Scribner's, 1970.

Gordon-Taylor, G., \& Walls, E. W. Sir Charles Bell: His life and times. Edinburgh and London: Livingstone, 1958.

Gulick, W. L., \& Lawson, R. L. Human stereopsis: A psychophysical approach. New York: Oxford University Press, 1976.

HeLмноLTz, H. voN. [Helmholtz's treatise on physiological optics] (Vol. 3, 3rd German ed.). (J. P. C. Southall, Ed. and trans.). New York: Optical Society of America, 1925. (Originally published, 1911.)

Hering, E. [Spatial sense and movement of the eye] (C. A. Radde, trans.). Baltimore: American Academy of Optometry, 1942. (Originally published, 1879.)

LE Conte, J. Sight: An expression of the principles of monocular and binocular vision. New York: D. Appleton, 1881.

Mackenzie, W. The physiology of vision. London: Longman, Orme, Brown, Green \& Longman, 1841.

Muelder, J. H. [Elements of physiology] (Vol. 1, 2nd ed.) (W. Baly, trans.). London: Taylor \& Walton, 1843 . (Originally published, 1840.)

ONo, H. Axiomatic summary and deductions from Hering's principles of visual direction. Perception \& Psychophysics, 1979, 25, 473-477.

Panum, P. L. [Physiological investigations concerning vision with two eyes] (C. Huebscher, trans.). Hanover, N.H: Dartmouth Eye Institute, 1940. (Originally published, 1858.)

Smiтh, R. A. Compleat system of opticks in four books. Cambridge: Author, 1738.

Wade, N. J. Sir Charles Bell on visual direction. Perception, 1978, 7, 359-362.

WeLLs, W. C. An essay upon single vision with two eyes; together with experiments and observations on several other subjects in optics. London: T. Cadell, 1792.

Wells, W. C. An essay on dew and several appearances connected with it. London: Taylor \& Hessey, 1814.

Wells, W. C. An account of a female of the white race of mankind, part of whose skin resembles that of a negro; with some observations on the causes of the differences in colour and form between the white and negro races of men (A paper read before the Royal Society in 1813). In W. C. Wells, Two essays: One upon single vision with two eyes; the other on dew. London: A. Constable, 1818.

Wells, W. C. Two essays: One upon single vision with two eyes; the other on dew. London: A. Constable, 1818.

Wheatrtone, C. Contributions to the physiology of vision. Part the first. On some remarkable, and hitherto unobserved, phenomena of binocular vision. Philosophical Transactions of the Royal Society, 1838, 128, 371-394.

\section{NOTES}

1. Given the modern distinction between the optic axis and the visual axis, the term visual axis should have been used throughout this paper. However, the term optic axis is used in order to be consistent with the quotations that follow.

2. The first experiment discussed by Wells used a piece of wire in the common axis, but because its illustration would be identical to that for the demonstration with one line in Figure 2 of Ono (1979), it is not illustrated here. Other stimuli used by Wells to test the three propositions were pins, needles, rulers, and pieces of colored string.

3. An argument might be made that Hering's theory is superior because it uses constructs or because there is a higher probability that the predictions will be confirmed when the perceived distance of the diplopic images is nonveridical. However, such an argument is not considered here because it would not contribute to the emphasis of this paper that Wells deserves greater recognition.

4. Why Bell $(1803,1823)$ did not reference this observation and idea is puzzling, because he should have had access to Wells's writings. He referred to Wells's observation on postrotational movement of afterimage, and thus was familiar with at least a part of the essay. Moreover, they were contemporaries in the teaching hospitals in the London area (Gordon-Taylor \& Walls, 1958). Wade (1978) correctly states that Bell preceded Heimholtz in stating the outflow theory, but Bell was not the first to publish data on the lack of apparent movement with passive cye movement.

(Manuscript received June 25, 1981; accepted for publication July 20,1981 .) 